\title{
The Concepts of Sustainable Organisation, Sustainable Human Capital Management and Organisational Resilience as Guidelines for the Modernisation of Healthcare Units in Poland
}

\author{
Tomasz Rostkowski, Jan Strzemiński, Karol Szymański \\ Institute of Human Capital, Collegium of Business Administration, \\ SGH Warsaw School of Economics
}

\begin{abstract}
A multitude of attempts to reform the Polish healthcare system cannot be treated as fully successful. Therefore, there is a need to determine new possible methods that can solve financial, social, and environmental problems burdening the system. Thus, the purpose of this article is to present necessary steps that have to be taken in order to conduct a successful reform. Moreover, the article presents an overview of the current state of the theory of sustainable organisation, sustainable human capital management and
\end{abstract}


resilience. Proper implementation of the key elements of the above-mentioned theories may turn out helpful in the process of modernisation of human capital management in the Polish healthcare system.

Keywords: sustainable human capital management, sustainable organisation, organisational resilience, healthcare

JEL Classification Code: M12

\section{Introduction}

Healthcare in Poland faces financial, social and environmental problems. Despite the repeated reforms, they have not been effectively resolved. One should, therefore, seek for new methods. The new approach may be inspired by the concept of sustainable development, which is not only visible in the Constitution as a guideline for the desired direction of the development of the entire economy, but also increasingly used by enterprises both in relation to the management of the entire organisation and its selected functions, including HCM (human capital management).

The aim of this article is to indicate the necessary changes in the approach to healthcare reform in Poland and the possibility of using the concept of sustainable development in practice of healthcare units. The implementation of such an objective requires the presentation of the concept of sustainable organisations, selected key healthcare problems and the assumptions of a sustainable HCM. This will allow for the identification of both the most useful theoretical approaches and the achievements of practice, as well as the recognition of key gaps in the available knowledge.

In the preparation of this article, the results of research conducted by the authors in 2019 for the Ministry of Health ${ }^{1}$ were used. The research consisted of three stages: development of a without-a-scenario demand model, in which analyses of the law concerning employment standards and the actual number of physicians working in hospitals were carried out, development of a supply model, in which the demand model was supplemented by the dynamics of the physicians as a resource, with a particular emphasis on demographic conditions and dynamics of physicians' education in Poland, and development of a model of physicians' work efficiency, in which field research was conducted to identify conditions of physicians' work efficiency in hospitals. A complementary source of knowledge were the study visits

1 Study on the stability of demand and supply of work of medical personnel in Poland, the task carried out under the project entitled: Health needs maps - System and implementation analysis database, cofinanced by the European Union from the resources of the European Social Fund under the Operational Programme Knowledge Education Development. 
carried out in 2020 and numerous consultations with practitioners, i.e., top managers of healthcare units and persons holding high positions in institutions of healthcare facilities. The analyses prepared by the students of MBA studies conducted by SGH Warsaw School of Economics and WUM Medical University of Warsaw were also an inspiration for finding effective solutions.

\section{Sustainable organisation and its key features}

When presenting the concept of organisation, one should first refer to the definition presented by Kotarbiński. It is "a kind of wholeness due to its own elements, namely a wholeness whose all components contribute to the success of this wholeness" (Kotarbiński, 1958, p.75).

Katz and Kahn have defined the organisation as a kind of social system that consists of elements such as organisational roles (understood as the behaviour of people performing specific tasks), norms that sanction those roles (understood as demands or expectations of people performing those roles) and values (understood as ideological justifications from which the norms stem) (Katz \& Khan, 1978).

The approach presented by Parsons, on the other hand, takes into account the particular importance of the purpose of actions undertaken. He stated that what distinguishes organisations from other social systems is their particular focus on achieving a specific, defined objective (Parsons, 1985).

For the purpose of this article, a definition is adopted that aggregates the different approaches. According to Leavitt, the organisation is a kind of orderly system that consists of four basic subsystems, that is:

- objectives pursued by the organisation;

- people, their patterns of behaviours and aspirations (both individual and group);

- elements of technical, material, and technological infrastructure, as well as specific rules for their use;

- principles of division of tasks, power, information, and responsibility for these components - understood as a formal structure (Leavitt, 1965).

Similarly to the concept of organisation, the term of sustainable organisation also has many definitions. Parrish understands a sustainable organisation as a kind of a set of activities that are part of the concept of sustainable development, whose overriding goal is to build people's future prosperity (Parrish, 2007).

Another approach to sustainable organisation is presented by Leon, who sees them as actors who, guided by ethical values, produce concrete plans and structures of action to achieve the economic, social, and environmental objectives of an economic unit on the economic, social and environmental grounds (Leon, 2013). 
A similar approach is presented by Przychodzen, who considers that a company should be regarded as sustainable if it is able to operate in the long term on the basis of effective management of all the essential aspects of its business, i.e., financial, social, and environmental (Przychodzeń, 2013).

For the purpose of this article, the definition developed by the SGH Institute of Human Capital team has been adopted in the course of statutory research on human capital management under conditions of sustainable development. A sustainable organisation is an organisation that remains permanently capable of meeting the needs of its customers, employees and other stakeholders (now and in the future) in a way that is acceptable to them, and which, in the face of changing environmental conditions, taking responsibility for the effects of its activities on the sustainability of resources, achieves the assumed effects in economic, social and natural safety terms, leading to synergistic benefits (for all its stakeholders).

This means that the necessary conditions for an organisation to be considered sustainable are:

- delivering value and meeting the needs of customers, employees and other stakeholders in the organisation;

- taking responsibility for the consequences of actions taken;

- ensuring the balance of resources, while achieving economic, social, and environmental effects;

- achieving synergy of actions taken;

- taking care of the sustainability of actions taken and implemented.

\section{Challenges of health protection in the context of the conducted research}

The healthcare system is one of the most complex economic structures. According to Mechanic, the key actions and objectives of the healthcare system should be to organise and provide services in such a way as to effectively relieve patients of their illness with the given resources (Mechanic, 1978).

The conditions for achieving the objectives defined in this way are to ensure, among other things:

- conditions for effective cooperation between the entities forming the system;

- stability of the functioning of healthcare entities;

- durability and ease of obtaining needed resources;

- availability and usefulness of the information base.

It is not possible to ensure the stability of the functioning of the system without ensuring an adequate number of medical staff as well as the quality and efficiency of 
their work. At this point it is impossible not to refer to international data concerning the number of staff per 1,000 inhabitants - in Poland we currently have just over 2 doctors $^{2}$ and 5 nurses ${ }^{3}$ per 1,000 inhabitants, which situates our country on the last place among the EU countries (OECD, 2018). An even more important aspect is the average age of doctors, ${ }^{4}$ which in the near future will translate into staff replacement and thus availability of service providers and services themselves. As the results of the research conducted by SGH Warsaw School of Economics 5 in 2019 clearly show, the only solution for Poland, from the perspective of the demographic situation among doctors, is to move away from extensive management of the working time of medical personnel and to care for high quality and efficiency of work.

The research carried out has highlighted the phenomenon of significant fragmentation in medical specialties. According to the EU indications, the number of medical specialisations should be around 55, while in Poland, we currently have nearly 90. In order to increase the effectiveness of the healthcare system in Poland, combining specialisations should be considered. In this way, a long period of specialised training could be compensated for by greater flexibility in human capital management. This should be complemented by certification schemes for professional competence (especially in the area of entirely new medical technologies and the LLL ${ }^{6}$ concept).

2 It should be noted that these statistics differ significantly from the indicators calculated on the basis of the data of the Supreme Chamber of Medicine. This is due to the difference in the definition of a doctor and a practising doctor. According to the Act on the Professions of Doctor and Dentist, a practicing doctor is considered to be any person who, having the necessary qualifications confirmed by a relevant diploma, provides healthcare to a patient, but also participates in scientific research in the field of medicine, carries out activities promoting health, teaching the medical profession, directs a therapeutic entity (according to Article 4 of the Act of 15 April 2011 on medical activity), is employed in the entity obliged to finance healthcare services from public funds (within the meaning of the Act of 27 August 2004 on healthcare services financed from public funds) or the offices servicing these entities, in which it performs duties related to the preparation, organisation or supervision over the provision of healthcare services. In this sense, the ratio of active doctors per 1,000 inhabitants is 3.59 (for 2018). According to the $\mathrm{OECD}$, an active doctor is the one directly involved in providing healthcare services to a patient, whose primary place of employment is a therapeutic entity.

3 According to the data of the Supreme Council of Nurses and Midwives - the number of registered nurses in Poland in 2018 was 288,731 (about 7.52 nurses per 1,000 inhabitants). Accordingly, the number of nurses employed was 233,012 (approx. 6.07 nurses per 1,000 inhabitants).

4 According to the National Medical Chamber data, the average age of a specialist doctor in Poland is about 57 years old.

5 Study on the stability of demand and supply of work of physicians in Poland, the task carried out under the project entitled: Health needs maps - System and implementation analysis database, cofinanced by the European Union from the resources of the European Social Fund under the Operational Programme Knowledge Education Development.

6 According to the OECD definition, 'lifelong learning' means "the conscious continuation of learning throughout life, in opposition to the idea that education ends at 16, 18 or 21 years of age. There are two aspects to this understanding. First of all, it [...] provides the opportunity to return to formal educational institutions and non-formal learning many times, which is conscious, planned and systematic. Secondly, it implies the recognition by individuals, employers, and authorities of points 
A key problem in strategic healthcare management is also the insufficient information base. The data currently available do not provide a fully reliable basis for developing multi-annual strategies for the health system as a whole or in individual areas of its operation. However, it is fully justified to use the most modern substantive solutions supported by the highest quality IT solutions (based on the concepts of competence management, talent management, work efficiency management). The existence of such IT solutions is an advantageous situation, and the problem is the total lack of adequate substantive solutions. Implementation of such solutions is a necessary condition for effective management of the medical staff in Poland.

The observations presented here are a few examples of the challenges currently faced by the healthcare system. The multitude and multidimensionality of problems allows us to suppose that the introduction of changes should combine elements of the concept of sustainable organisation and sustainable human capital management.

\section{Symptoms of sustainability of organisations in healthcare}

The review of the literature on the subject, as well as observations of the practice of healthcare entities make it clear that they do not function according to the presented concept of sustainable organisations. Their actions are only single manifestations of the pursuit of sustainability.

Achour and Price describe such practices. As noted by the researchers, the dynamic development of technology has a direct impact on the degree of use of individual devices and tools used in healthcare. This fact, combined with the high level of energy inefficiency of buildings in which health services are offered and provided, has a strong impact on the level of carbon dioxide released into the atmosphere (Achour \& Price, 2010). The UK's environmental commitments and the fact that the $\mathrm{NHS}^{7}$ contributors were the biggest polluters have highlighted the need to develop emission reduction strategies. ${ }^{8}$ Its implementation and evaluation is a manifestation of the pursuit of environmental sustainability. At the same time, the actions taken have contributed to improving the resilience of healthcare units.

Another source of inspiration, showing the pursuit of sustainability, is the Kaohsiung Municipal Min-Sheng hospital in Taiwan (Achour \& Price, 2010). In 2001,

where there is a social and/or economic need to update knowledge and skills. The latter aspect differs from the former, as it not only sees continuing education as a right, but a necessary requirement for participation" (OECD, 1997).

7 The National Health Service.

8 In 2008, the NHS and its subordinates emitted about one million units of $\mathrm{CO}_{2}$ per year. After: The health impact of climate change: Promoting sustainable communities (2008). 
the hospital was flooded, leading to a total shutdown for three days and the loss of 500,000 patients' health data. As a result of the event, rules were developed for dealing with natural disasters, which is at the same time a desire to balance the organisation. The lack of staff and social aspects should be considered as a disadvantage of this solution. Therefore, this example should only be seen as an attempt at sustainability, and not as a coherent action to effectively build sustainability of the organisation.

The presented examples seem to be reflected in the conditions of the Polish healthcare system. According to the research conducted in 2019 by SGH Warsaw School of Economics, ${ }^{9}$ the necessary action allowing the organisation to strive for its sustainability is to develop an integrated model of competence management in healthcare and to develop objective, logically related competence, organisation, quality, efficiency and financial measures in the field of human capital management in healthcare. It is important to develop sets of good practices and on their basis to develop certification mechanisms focused on the results achieved, which include:

- developing skills;

- improving work and making it more efficient;

- improving the quality of services provided;

- improving job satisfaction, including pay;

- improving the financial situation of hospitals in Poland.

\section{Theoretical concepts of sustainable HCM}

The presented definition of a sustainable organisation underlines the dual nature of the analysed phenomenon. On the one hand, sustainability refers to the interior, i.e., the structure, resources, and functions of an organisation. On the other hand, the role of relations and forces interacting between an individual and the environment in which he or she functions becomes visible.

The relationship between human capital management and the sustainability of an organisation should be considered from the perspective of sustainability, among others:

- the function of human capital management, its proper processes, and the dynamics of the organisation;

- in terms of resources, including human resources, forming the organisation;

\footnotetext{
9 Study on the stability of demand and supply of work of doctors in Poland, the task carried out under the project entitled: Health needs maps - System and implementation analysis database, cofinanced by the European Union from the resources of the European Social Fund under the Operational Programme Knowledge Education Development.
} 
- with regard to the acquisition of human resources from the organisation's environment.

The first two research perspectives include definitions based on human capital management models. In the literature on the subject, we particularly often find definitions of sustainable HCM based on the Michigan ${ }^{10}$ model, i.e., relating sustainability to the processes that create it. This trend includes some important definitions:

- Ehnert, who defines sustainable HCM as "long-term conceptual approaches and activities aimed at socially responsible and economically appropriate recruitment and selection, development, deployment and reduction of employees" (Ehnert et al., 2014, p. 215);

- Zaugg and Thom, who define sustainable HCM as "a long-term, socially responsible human resource management policy focusing on the implementation of appropriate, transparent recruitment and retention procedures, training and development, performance and motivation management and employee involvement" (Thom \& Zaugg, 2004, p. 217).

The resource perspective is complemented by treating sustainable HCM as a tool to build sustainability of resources available in the organisation. The results of Marhatta and Adhikari's research, who use the term 'green human resource management,' are part of this trend. It is defined as "a policy applied to promote the sustainable use of the organisation's resources with an aim of environmental sustainability" (Marhatta \& Adhikari, 2013, p. 13). Thus, the role of sustainable HCM is limited to complementing and supporting the organisation's quest for sustainability.

A similar approach can be found in the research of Mazur, who indicated the areas and tasks of HCM supporting organisational sustainability. These include leadership development or cooperation and teamwork, but also training and development, as well as health and safety (Mazur, 2014).

The focus on effectiveness and efficiency of actions is contained in the definition proposed by Kramar, which states: "sustainable HRM refers to the social and human performance that contributes to the long-term sustainability of the organisation" (Kramar, 2014, p. 1069).

From the last of the research perspectives, sustainable human capital management is reduced to ensuring sustainable access and opportunities to acquire employees from the organisation's environment. As part of a sustainable approach, it is necessary to clarify the interaction between organisations and their environments and to develop an overall theoretical approach to dealing with scarce resources.

10 More in: Pocztowski (2003). 
In the course of the systematic review, scientific publications containing all of the above perspectives were identified. For the purpose of this work, sustainable HCM is defined as a set of activities concerning the acquisition, retention, motivation and development of employees carried out in such a way that the pursuit of the highest efficiency of work thanks to the synergy effect also has a positive impact on the welfare of employees, their families and other persons related to the organisation and the achievement of economic, social, and natural safety results by the organisation.

\section{Sustainable HCM in the Polish healthcare system}

The research conducted in 2019 by SGH Warsaw School of Economics ${ }^{11}$ revealed that a real problem in Poland is to ensure generational substitution of staff among key groups of employees. In addition, analyses carried out by students of MBA studies at SGH Warsaw School of Economics (SGH - WUM) clearly indicate a significant backwardness of hospitals in the implementation of modern solutions in the field of human capital management, and a widespread lack of appropriately competent specialists in the field of HCM in Polish hospitals and their unavailability on the labour market. Adopted, often very time-consuming and excessively bureaucratic methods of action cause significant limitations in the effectiveness of physicians' work. It is worth pointing out that we are dealing with this kind of situation despite years of reforms. In Poland, a set of standards has been developed and implemented, covering not only issues such as continuity of care, assessment of the patient's condition and information management, but also a significant area of human resource management (CMJ, 2009/2016).

The prepared standards cover almost all key areas of human capital management. Meeting these standards is necessary to obtain accreditation, which, in turn, means significant, measurable benefits for hospitals, not only in terms of image, but also financial. For these reasons, the accreditation programme is very popular in Poland (CMJ, 2020). However, its application has not produced positive results in terms of the creation of integrated human capital management systems.

On the one hand, the accreditation mechanism seems to be effective, on the other hand, compliance with the guidelines has not brought about any significant progress. This raises the question of the future of human capital management in hospitals and further improvements. There are several challenges: increasing the financial

11 Study on the stability of demand and supply of work of doctors in Poland, the task carried out under the project entitled: Health needs maps - System and implementation analysis database, cofinanced by the European Union from the resources of the European Social Fund under the Operational Programme Knowledge Education Development. 
efficiency of hospitals, improving the availability and quality of medical services, increasing the satisfaction from healthcare for both patients and their families, as well as medical staff. The above collection fully complies with the definition of the conditions to be met by a sustainable organisation. For this reason, it is the achievements of this part of the theory that may serve to lay the foundations for sustainable human capital management in healthcare in Poland.

The first guideline for sustainable organisations that can be used to address the problem of the HCM in healthcare is about providing value. The HCM in healthcare should be aimed at a measurable solution to the problem of maintaining health, while respecting other stakeholders, among which the most important are the entity paying for the services, patients and their families, as well as employees.

Secondly, a hospital operating on the basis of the principles of sustainable organisations must take responsibility for the consequences of its actions and for the consequences of possible omissions. In the area of HCM, this means that there must be clear guidelines not only on the taking of specific initiatives by employees, but also guidelines for deciding not to take action, if taking action, although beneficial in the short term, could mean significant problems for all stakeholders in the long term (e.g., addressing additional medical challenges leading to the bankruptcy of the hospital due to its debt).

Thirdly, the concern to maintain balance in achieving economic effects means that the financial perspective must be adopted as the basic limiting guideline. This involves recognising that the financial and other resources available to the hospital are limited and must be used in such a way as to maximise their impact in the short and long term. The need to care for the environment must be seen not as a source of potential loss but, on the contrary, as an inspiration to take action to save both material resources and, above all, the time of medical personnel. For example, the need to reduce paper consumption should also result in a reduction in the labour intensity of processes. In this way, another postulate in the form of the need to achieve synergistic effects will also be implemented. All actions in the area of human capital management must be taken in such a way that they serve the health and life of patients, at the same time being carried out at a constantly reduced unit cost and with the minimisation of negative environmental effects, the list of which in the case of hospitals is much longer than that of most organisations, because regardless of the countermeasures taken, it is hospitals that are the primary epidemic threat.

All these demands must be implemented at the same time, taking into account the significant implementation difficulties in the form of:

- continuous crises and conflicts within the health system, as well as within the individual organisations that create it; 
- lack of competent specialists in human capital management with experience to understand the specifics of hospitals and healthcare more broadly;

- a permanent shortage of specialists resulting from the long-term training cycle of both doctors, nurses, and other medical personnel.

The use of the hitherto achievements of the theory and practice of human capital management is not sufficient, and the proposed solution must not only derive from the most modern instrumentation of HCM, but also completely new concepts of change management, which will not only enable the implementation of the proposed solutions, but ensure their sustainability.

\section{Flexible resilience as a guarantee of achieving lasting effects in healthcare}

Resilience, as a feature of an organisation, is included in the field of social sciences, and in particular, in the management theory. In the literature on the subject we do not find an unambiguous, commonly accepted definition of resilience (Lisnyak, 2015). Originally, the term was interpreted as the possibility of returning to the initial state of the system after a shock, defined as a sudden change affecting all aspects of its functioning. The basis for this definition were biological sciences and the research subject were ecosystems.

The theory of resilience developed in the 1970s. An important contribution to this process was the research by Holling, who combined the system theory and ecology with simulation modelling and policy analysis. ${ }^{12}$ According to the definition of the cited author, immunity is "a measure of the durability of systems and their ability to incorporate changes and disturbances and maintain the same relationships between populations or state variables" (Holling, 1973, p. 17).

Rose (2004) made the theory of resilience more detailed, distinguishing between its primary and secondary varieties. The first is determined by the current capacity of the system to absorb shocks and their effects, to limit future vulnerability and the time needed to recover. Secondary resilience is the ability of a system to acquire and use additional resources and solutions to resist external forces and recover.

A different classification of resilience was proposed by Hill. According to his theory, systems are characterised by different types of resilience:

${ }_{12}$ C.S. Holling sought to develop an integrated theory of change, which allowed him to introduce concepts commonly used in ecology and evolution, including resilience, adaptive management, adaptive cycle and panarchy. 
- flexible - when a shock occurs, the system is not only able to return to its original state, but can also improve its functioning in the short term;

- resistant - when the system returned to its original state in a situation of shock, but the dynamics of its development were distorted (Hill et al., 2008).

It is noticeable that, originally, the theory of resilience referred only to systems, i.e., assemblies of interconnected elements that together serve a specific purpose. According to the systems theory, resilience can be defined as the external manifestation of their internal structure. In order to increase their resilience to shocks, the systems themselves and their components should primarily be improved (Mileti, 1999). In order to guarantee the resilience of the healthcare system, holistic solutions are necessary, i.e., with regard to all its participants and their specific resilience characteristics.

It follows from the above considerations that the use of the concept of creating flexible resilient organisations, i.e., the ones that use difficulties and shocks for selfimprovement, can be a valid theoretical proposal for healthcare.

\section{Conclusion}

Healthcare in Poland faces both financial (resulting from a permanent problem of underfunding) and social problems, which emerge both from the mission of healthcare and serious problems with the availability of an adequately numerous human capital. Additionally, pro-environmental actions of healthcare must result not only from the reasons similar to those in other organisations, but also from epidemic threats which healthcare units are the source of. It is clear from the above that the inspirations available thanks to the concept of sustainable organisations and sustainable HCM may be very valuable for solving complex healthcare problems in Poland.

Many years of experience with attempts to modernise healthcare as a system do not bring positive results. The centrally introduced changes, both those enforced by legal standards and financial incentives, have not proved effective. At the same time, the research carried out indicated a very large variation in the objective needs of the individual units making up the healthcare system. This diversity results both from the scope of a unit's tasks, its specificity, ownership conditions and local labour market, and the health needs of Poles. In addition, it should be pointed out that the 'system' of healthcare is made up of units and persons who not only do not have to share common objectives but, on the contrary, often compete for both public and private resources. For this reason, consideration should be given to moving away from topdown and revolutionary implementation of change to bottom-up and evolutionary implementation of modernisations, while retaining the possibility of appealing for support to the units playing a decision-making role in the system. 
In order to achieve such objectives, it is necessary to refer to the best practices of human capital management developed in other sectors, as no solutions that could serve as good practices have been identified in Poland so far. As it seems particularly good results are to be expected from the concept of building integrated competence management systems. The lack of professional HR staff specialised in healthcare indicated in this article is an important problem, but also an opportunity. It consists in the possibility of omitting intermediate stages and attempting to immediately implement the most effective solutions, i.e., integrated computer-assisted HCM systems and introducing the HRBP concept (Ulrich, 2001), i.e., moving away from only the supporting concept and implementing active support for managers and employees by HR specialists.

The attention paid to bottom-up implementations should quickly result in sets of good practices, which are likely to be diverse due to the diverse problems faced by healthcare units in Poland.

The theoretical and practical challenge is to develop and operationalise the concept of flexible resilience and its adaptation to the needs of the individual units that make up the healthcare system and, consequently, to the whole system.

\section{References}

Achour, N., \& Price, A.D.F. (2010). Resilience strategies of healthcare facilities: Present and future. International Journal of Disaster Resilience in the Built Environment, 1(3), 264-276.

CMJ (2009/2016). Program Akredytacji. Szpitale, zestaw standardów. Kraków: CMJ (edition renewed in 2016).

CMJ 2020, Lista szpitali z aktualnym certyfikatem akredytacji. Retrieved from: https:// www.cmj.org.pl/akredytacja/certyfikaty.php (30.5.2020).

Ehnert, I., Wes, H., \&Zink, K.J. (2014). Sustainability and human resource management: Developing sustainable business organizations. Berlin: CSR, Sustainability, Ethics \& Governance, 215.

Hill, E., Wial, H., \& California, B. (2008). Exploring regional economic resilience. Working paper. Berkeley: University of California, Institute of Urban and Regional Development.

Holling, C.S. (1973). Resilience and stability of ecological systems. Annual Review of Ecology and Systematics, 4, 17.

Katz, D., \& Khan, R.L. (1978). The social psychology of organizations. New York: Wiley, 64. Kotarbiński, T. (1958). Traktat o dobrej robocie. Wrocław-Warszawa: Zakład Narodowy im. Ossolińskich, 75. 
Kramar, R. (2014). Beyond strategic human resource management: Is sustainable human resource management the next approach? The International Journal of Human Resource Management, 25(8), 1069.

Leavitt, H.J. (1965). Applied organizational change in industry. In: G. March (Ed.), Handbook of organization. Chicago: Rand McNally and Company, 160.

Leon, R.D. (2013). From the sustainable organization to sustainable knowledge-based organization. Economic Insights - Trends and Challenges, 2, 63-73.

Lisnyak, S. (2015). Literature review regarding the concept of resilience and its assessment in the context of the economic dimension. Alexandru Ioan Cuza University, CES Working Papers, Centre for European Studies, 7(2a), 511-518.

Marhatta, S., \& Adhikari, S. (2013). Green HRM and sustainability. International Journal of Ongoing Research in Management, 13.

Mazur, B. (2014). Sustainable human resource management in theory and practice. Economics and Management.

Mechanic, D. (1978). Medical sociology. New York-London: The Free Press, 315.

Mileti, D. (1999). Disasters by design: A reassessment of natural hazards in the United States. Washington, DC: Joseph Henry.

OECD (1997). Lifelong learning for all. Paris.

OECD (2018). Retrieved from: https://data.oecd.org/healthres/doctors.htm (30.5.2020). Parrish, B.D. (2007). Designing the sustainable enterprise. Futures, 39(7), 846-860.

Parsons, T. (1985). Sugestie dla socjologicznej teorii organizacji. In: A. Marcinkowski, B. Sobczak (Eds.), Wybrane zagadnienia socjologii organizacji Cz.I. Kraków: Uniwersytet Jagielloński, 65.

Pocztowski, A. (2003). Zarzqdzanie zasobami ludzkimi. Warszawa: Polskie Wydawnictwo Ekonomiczne.

Przychodzeń, W. (2013). Zrównoważone przedsiębiorstwo. Warszawa: Poltext.

Rose, A. (2004). Defining and measuring economic resilience to disasters. Disaster Prevention and Management, 13(4), 307-314.

Thom, N., \& Zaugg, R.J. (2004). Innovation and personal management. In: E.J. Schwarz (Ed.), Innovations management. Wiesbaden: Gabler, 217.

Ulrich, D. (2001). Liderzy zarzqdzania zasobami ludzkimi. Nowe wyzwania, nowe role. Kraków: Oficyna Ekonomiczna.

\section{Tomasz Rostkowski}

Associate Professor at SGH Warsaw School of Economics, Head of the Human Capital Management Unit (in the Institute of Human Capital). He has been working in HR for 20 years. He worked in consulting in the Neumann Management Institute, co-founded and then was the Chairman of the Board in HRK Partners S.A., and served as the HR Director - the Board's Plenipotentiary. He designed HCM 
tools and led various projects in the area of building and optimising organisations. His specialties are developing HR management strategies and designing effective management systems. He is also experienced in development projects consulting (designing competence systems, appraisal systems and AC/DC tools) as well as advising on change management projects at the level of legal regulations (state), employer groups and public organisations, as well as individual enterprises and worker groups. He has conducted numerous conferences and symposia. He is the author of a great many books and over 100 articles on Human Capital Management issues. He cooperates with various entrepreneurs and public institutions both in Poland and abroad.

e-mail address: tomasz.rostkowski@sgh.waw.pl

ORCID: 0000-0002-3932-5692

\section{Jan Strzemiński}

A graduate of SGH Warsaw School of Economics, engaged in activities for the most important persons and institutions forming the healthcare system in Poland. He specialises in the automation of business processes, analysis of the level of effectiveness of healthcare entities and introduction of changes conducive to its development. He participates in numerous activities for the development of competences of persons involved in healthcare.

e-mail address: strzeminski.jan@gmail.com

ORCID: 0000-0003-1607-8710

\section{Karol Szymański}

Co-worker at the Institute of Human Capital of SGH Warsaw School of Economics, graduate of international economic and managerial relations. He deals with the proper use and adjustment of the system of non-wage benefits to the needs of employees and is preparing a doctoral dissertation in this area. He participates in projects for educational and healthcare institutions in Poland. Involved in efforts to modernise health management.

e-mail address: szymanski24@gmail.com

ORCID: 0000-0003-4711-4681 